\title{
Analysis of HVDC breakdown characteristic of LLDPE- natural rubber added with biofiller as high voltage insulating material
}

\author{
Nor Izzati Mohd Salleh ${ }^{1}$, Nor Akmal Mohd Jamail², Nishanti Suntharasakan ${ }^{3}$, Nor Shahida Mohd \\ Jamail $^{4}$, Mohamad Farid Sies ${ }^{5}$, Qamarul Ezani Kamarudin ${ }^{6}$, Mohamed Afendi Mohamed Piah ${ }^{7}$ \\ 1,2,3 Faculty of Electrical and Electronic Engineering, Universiti Tun Hussein Onn Malaysia, Malaysia \\ ${ }^{4}$ College of Computer and Information Sciences Prince Sultan University, Saudi Arabia \\ 5,6 Faculty of Mechanical and Manufacturing Engineering, Universiti Tun Hussein Onn Malaysia, Malaysia \\ ${ }^{7}$ Institute of High Voltage \& High Current (IVAT), Faculty of Electrical Engineering, UTM, Malaysia
}

\section{Article Info}

Article history:

Received Apr 1, 2020

Revised May 25, 2020

Accepted Jun 26, 2020

\section{Keywords:}

High voltage direct current (HVDC)

Linear-low density

Natural rubber (NR)

Oil palm empty fuit bunch

(OPEFB)

Pineapple leaf fiber (PALF)

Polythylene (LLDPE)

\begin{abstract}
The influence of solid insulation has been investigated by few researchers. The mechanism of solid breakdown is important in insulation studies. In this research, testing on linear-low density polythylene (LLDPE) with natural rubber (NR) and different weight concentration of biofiller are conducted under high voltage direct voltage (HVDC) by using needle and sphere types of electrode arrangements. Oil palm empty fruit bunch (OPEFB) and pineapple leaf fiber (PALF) are the biofillers used for the samples development. The LLDPE-NR samples consists of different weight percentages of biofiller which are $0 \%, 2.5 \% .5 .0 \%$. $7.5 \%$ and $10 \%$ with $3 \mathrm{~mm}$ thickness. The voltage has been increased until the breakdown occurs. Based on the results obtained, OPEFB and PALF with the highest weight percentages of $10 \%$ showed the highest damage voltages of $59.09 \mathrm{kV}$ and $59.36 \mathrm{kV}$. It has been proven that both samples with the highest filler content have appropriate insulating properties. In conclusion, the addition of biofiber to LLDPE-NR has improved the breakdown properties compared to pure LLDPE.
\end{abstract}

Copyright $\odot 2020$ Institute of Advanced Engineering and Science. All rights reserved.

\section{Corresponding Author:}

Nor Akmal Mohd Jamail,

Department of Electrical Power Engineering, Faculty Electrical and Electronic Engineering,

Universiti Tun Hussein Onn Malaysia,

86400 Parit Raja, Batu Pahat, Johor, Malaysia.

Email: norakmal@uthm.edu.my

\section{INTRODUCTION}

Solid insulation forms a fundamental part of high voltage structure. The solid materials run the motorized support for directing parts and at the same time, the insulator will insulate the conductors from one another [1]. In this study, the focus is on testing the breakdown characteristics of XLPE insulation cable by varying the bio filler of oil palm empty fruit bunch (OPEFB) and pineapple leaf fiber (PALF) with epoxy matrix Linear-Low Density Polyethylene (LLDPE) and Natural Rubber (NR) [2]. Cross-linked polyethylene (XLPE) is extensively used for communication cables [3]. Cross-linked polyethylene (XLPE) is an arrangement of polyethylene with cross-links. Cross-linking may be through or after extrusion of tubes where cross-linking is introduced into the polymer structure, transforming thermoplastics into elastomers. Currently, some XLPE cables have been around for 30 years and have been designed to date in their invention. In addition, the XLPE is more conventional for submarine cables than underground cables [4]. The issue of XLPE cable has been that the main material used is plastic polymer [5]. Malaysia is in the highest 3 highest sources of plastic waste globally [6]. It can cause weather change and less partial fossil fuel incomes. 
Therefore, due to environmental issues, it is important to go for green technology in the field of materials science regarding the growth of biocomposites and compost without harming the environment. Both bio filler will be combined with the epoxy matrixes which are LLDPE and NR as the tensile strength might be improved by adding another concentration as it has the interaction between the polymer molecules due to the increase of interfacial surface area [7].

Oil palm empty fruit bunch and pineapple leaf fiber are listed in the secondary plant which means fiber is produced. Oil palm empty fruit bunch reached $65 \%$ cellulose, $0 \%$ hemicellulose, $29 \%$ lignin, $0 \%$ waxes, 248( $\mathrm{MPa})$ tensile strength, $25 \%$ elongation at break, $0.7-1.55(\mathrm{~g} / \mathrm{cm} 3)$ density. Pineapple leaf fiber (PALF) reached $81 \%$ cellulose, $0 \%$ hemicellulose, $12.7 \%$ lignin, $0 \%$ waxes, 400-627(MPa) tensile strength, $14.5 \%$ elongation at break, $0.8-1.6(\mathrm{~g} / \mathrm{cm} 3)$ density, inexpensive and available. It is also reinforced with polycarbonate to produce several of composites $[8,9]$. LLDPE is selected because of the smallest destruction and lowermost standardized degradation index during the mixing progression relate to the other thermoplastic. It has a density characteristics of $0.918 \mathrm{~g} / \mathrm{cm} 3$, melt flow index of $1.0 \mathrm{~g} / 10$ minutes and melting temperature at the range of $120^{\circ} \mathrm{C}-160^{\circ} \mathrm{C}$ [10]. $\mathrm{NR}$ is used because it grows some interphases with the LLDPE matrix and provides a good way to the development of insulation [11]. According to the compound of $80 \%$ of LLDPE and $20 \%$ of NR with the ratio arrangement of 80:20 are designated as the base polymer in this testing [12].

\section{RESEARCH METHOD}

This research consists of several stages. First stage is the samples development and second stage is HVDC breakdown test.

\subsection{Samples Development}

This project requires LLDPE, NR, OPEFB and PALF to prepare the 10 samples in order to determine the variation of breakdown voltages among different fiber and composition of material. LLDPE is used as base matrix and mixed with NR. $80 \%$ of LLDPE and $20 \%$ of NR ratio is used as the base of the composite along with biofiller.The weight percentage (wt \%) of biofiller mixed with LLDPE and NR are $2.5 \%, 5 \%, 7.5 \%$ and $10 \%$. The chosen weight percentage are depends on the quantity of material available as well as to cover from $1 \%$ to $10 \%$. LLDPE and NR are selected as it is mentioned in the introduction. Figure 1 shows the material of LLDPE, NR, OPEFB and PALF. Figure 1 shows the 10 samples tested under HVDC breakdown test and Figure 2 shows the flowchart of samples development:

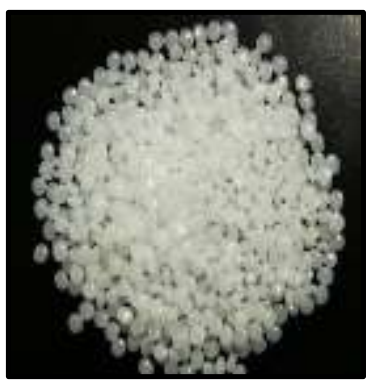

(a)

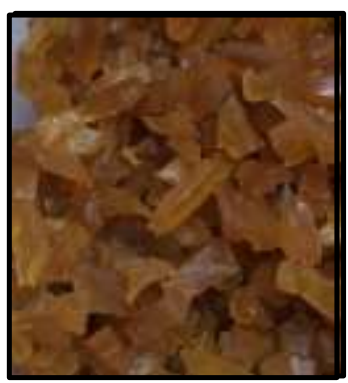

(b)

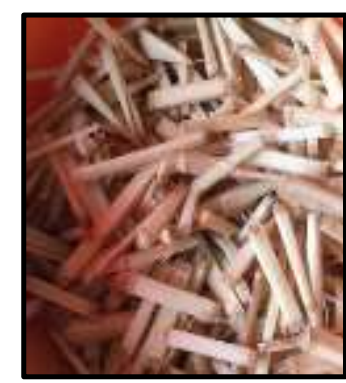

(c)

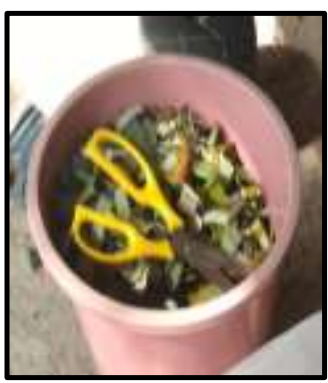

(d)

Figure 1. (a) LLDPE (b) NR (c) OPEFB (d) PALF

The supplier has been supplied for Natural Rubber, LLDPE, OPEFB and PALF (Table 1). Next, for the compounding process of polymer biocomposite, the NR has been mixed and blended with biofiller. The polymer biocomposites are prepared at $170^{\circ} \mathrm{C}$ using Brabender mixer. This Brabender mixer is controlled at $35 \mathrm{rpm}$ and the mixing duration is about 4 minutes for each sample. Lastly, compression molding is a process used to make stock shape materials which are both thermoplastic and thermoset. This is achieved by placing materials by adding heat and pressure. The sample has been prepared by using Hydraulic Hot press genesis brand manufacturing by Wabash MPI USA. This material is prepared into square shaped with a dimension of $24 \mathrm{~cm} \times 24 \mathrm{~cm} \times 0.3 \mathrm{~cm}$ and the thickness of $3 \mathrm{~mm}$ is obtained by hot melt pressing at $170^{\circ} \mathrm{C}$ for 10 minutes. Figure 2 shows the ten samples development that has been done based on Table 1 . 
Table 1. Designation and composition of OPEFB and PALF

\begin{tabular}{ccccc}
\hline \multirow{2}{*}{ Designation } & $\begin{array}{c}\text { Low Linear Density } \\
\text { Polyethylene (LLDPE) }\end{array}$ & $\begin{array}{c}\text { Weight percentage (wt. \%) } \\
\text { Natural Rubber } \\
\text { SMR CV60 }\end{array}$ & $\begin{array}{c}\text { Oil Palm Empty Fruit } \\
\text { Bunch (OPEFB) }\end{array}$ & $\begin{array}{c}\text { Pineapple Leaf } \\
\text { Fibre (PALF) }\end{array}$ \\
\hline A & 80 & 20 & - & - \\
B & 80 & 20 & 2.5 & - \\
C & 80 & 20 & - & - \\
D & 80 & 20 & - & - \\
E & 80 & 20 & 5 & - \\
F & 80 & 20 & - & 5 \\
J & 80 & 20 & - & - \\
H & 80 & 20 & 7.5 & - \\
I & 80 & 20 & - & - \\
J & 80 & 20 & - & - \\
K & 80 & 20 & 10 & - \\
L & 80 & 20 & - & 10 \\
M & 80 & 20 & - & \\
\hline
\end{tabular}

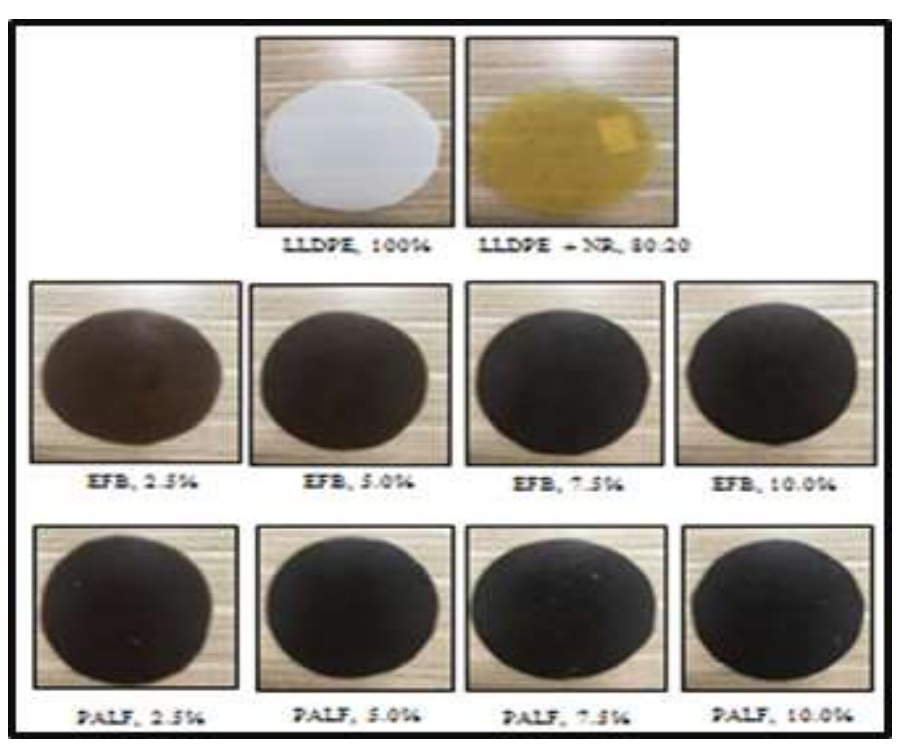

Figure 2. 10 samples development tested under HVDC breakdown test

\subsection{HVDC Breakdown Test}

This subtopic is more about the HVDC breakdown test that has been carried out. The DC breakdown voltage measurement method is referred to the TERCO instruction sheet in the high voltage laboratory. For this test, DC voltage is applied to get the data of breakdown test for ten samples consisting of pure LLDPE (references), LLDPE+NR and LLDPE+NR+biofiller with added wt $\%$ of $2.5 \%, 5 \%, 7.5 \%$ and $10 \%$. The samples are placed between two types of electrodes which are needle $(0.5 \mathrm{~cm}$ width $)$ and sphere $(5.5 \mathrm{~cm}$ width). The sample is flanked between two electrodes and there is no space between it. The samples are tested continuously until the sample is fully breakdown and there are hissing and explosion sound when a breakdown occurred. Then, for this experiment the control desk voltmeter is used to observe the DC breakdown voltage values. Figure 3 shows the HVDC experimental arrangement, arrangement of needle electrode to spherical electrode and control desk voltmeter: 


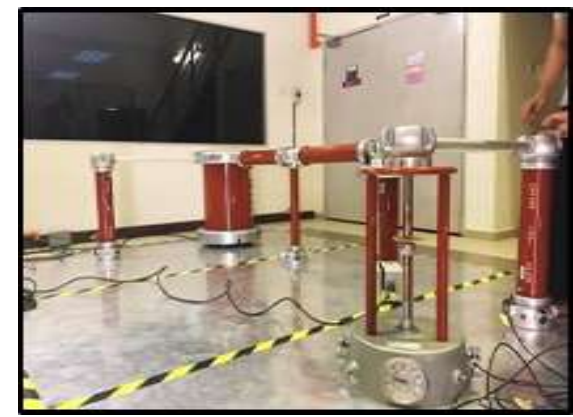

(a)

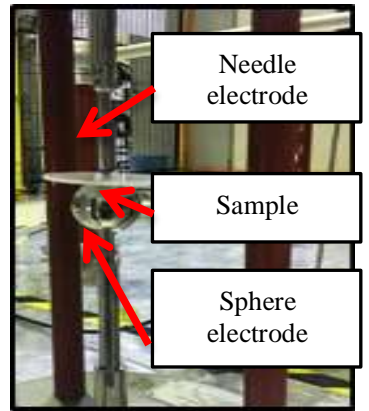

(b)

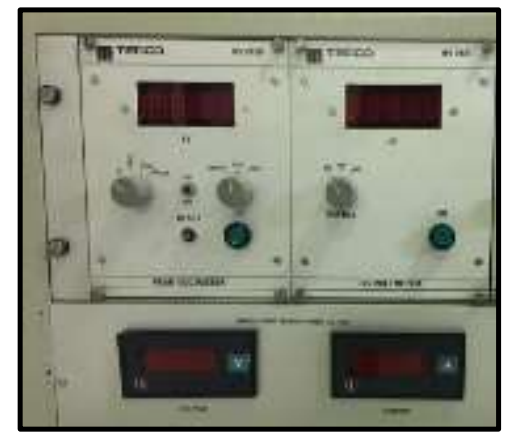

(c)

Figure 3. (a) HVDC equipmental arrangement (b) Electrode arrangement needle to sphere electrode

(c) Control desk voltmeter

\section{RESULTS AND DISCUSSION}

Each sample has undergone 6 times of breakdown voltage test. The sample is injected with maximum voltage and tested repeatedly until it is completely breakdown with a standard IEC 60502 [13]. The Table 2 and Table 3 show six breakdown voltage readings and from those values the average breakdown voltage is calculated. Based on the weight percentages of $2.5 \%, 5.0 \%, 7.5 \%$ and $10 \%$, [10] both samples containing fiber produced the highest breakdown voltage values when added with the weight percentage of the fiber. The Table 2 shows the DC breakdown voltage test conducted on LLDPE+NR+OPEFB/PALF $[14,15]$ :

Table 2. DC breakdown voltage test conducted on LLDPE + NR + OPEFB

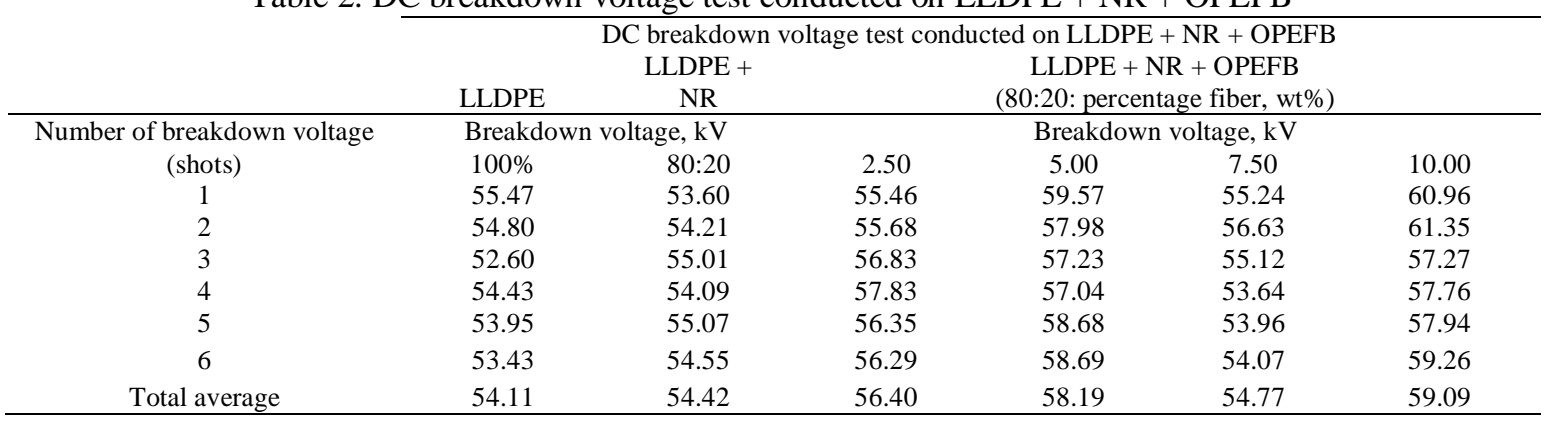

Table 3. DC breakdown voltage test conducted on LLDPE + NR + PALF testing

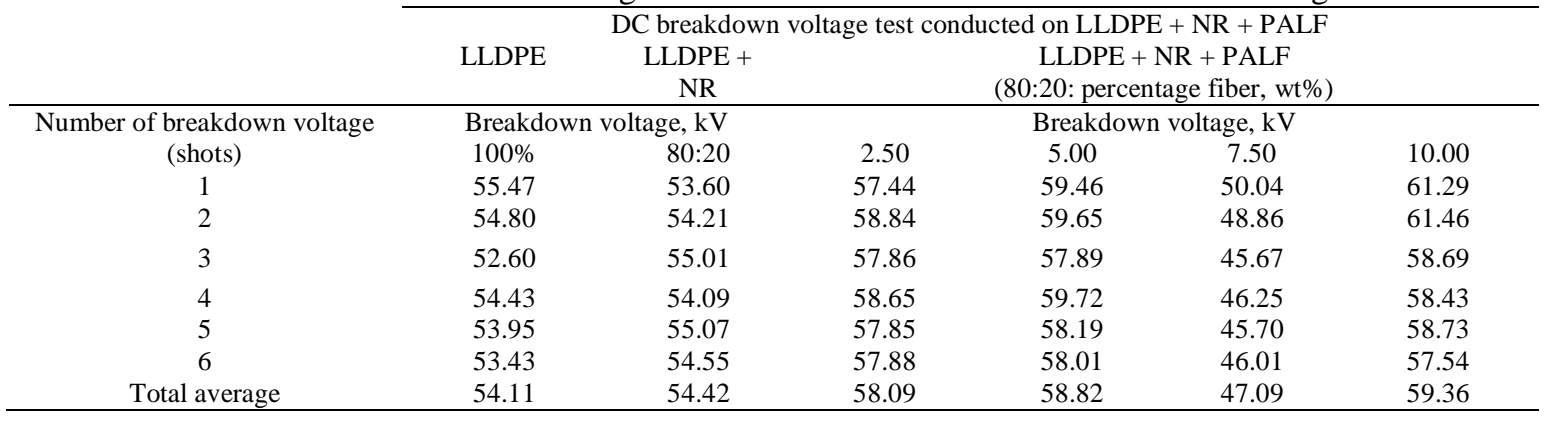

According to the total average values at Table 2 and Table 3, Figure 4 shows the graph of HVDC breakdown voltage test, $\mathrm{kV}$ versus the weight percentage of fiber, wt $\%$. Based on the Figure 3 , the line graph shows that the breakdown voltage has increased when pure LLDPE is added with natural rubber and fiber. However, the HVDC breakdown voltage for PALF yielded higher value compared to OPEFB which is $59.36 \mathrm{kV}$ and $59.09 \mathrm{kV}$ respectively. Moreover, another weight percentage value for PALF under HVDC breakdown test shows the increment compared to breakdown voltage of OPEFB. There are decreased voltage 
values for both PALF and OPEFB at $7.5 \%$ and the DC breakdown voltage values have increased again at $10 \%$.

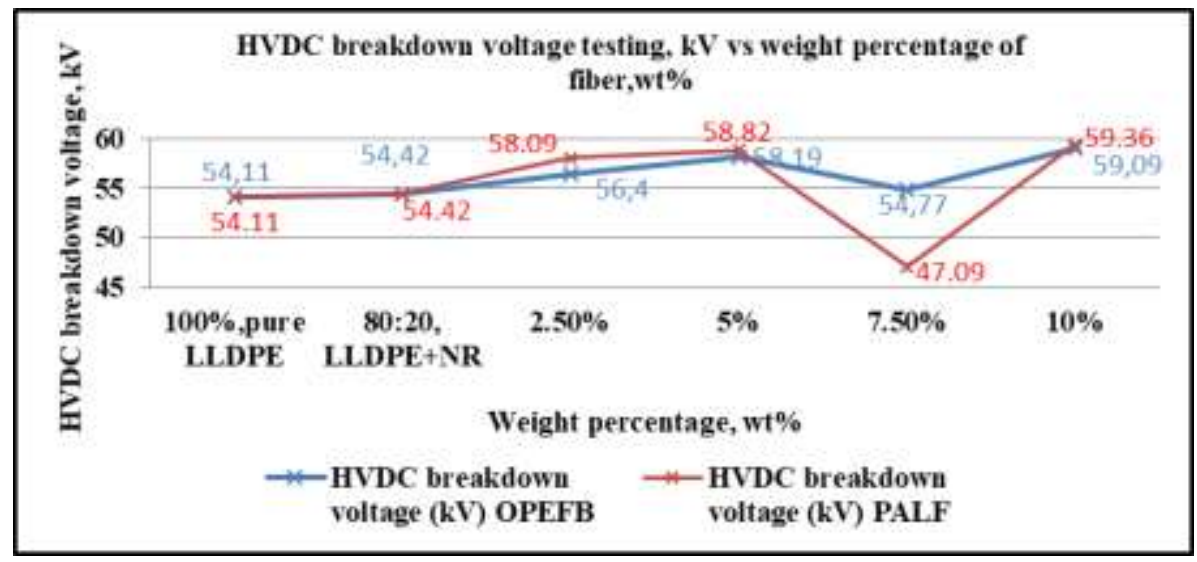

Figure 4. Line graph HVDC breakdown voltage testing versus weight percentage of fiber

From the mechanical properties, the fiber contains cellulose, lignin and hemicellulose. Cellulose is the most important part in the fiber as cellulose is given as a sign of the strength properties. Besides, cellulose is from the cotton plants and trees which substitutes the petroleum feedstocks to make cellulose plastics. Moreover, the value of cellulose for PALF is $81 \mathrm{wt} \%$ while for OPEFB it contains $65 \mathrm{wt} \%$ of cellulose [7]. Therefore, the value of breakdown voltage for PALF is higher compared to OPEFB as PALF contains more cellulose thus the resistivity and strength higher than OPEFB. The $10 \%$ of weight percentage is most suitable for insulation characteristic as shown in the HVDC breakdown test. Addition of microfiller is proven to improve the breakdown properties of the sample due to interaction between the filler and base material which enhances the degradation of the sample and improving the insulator to become stronger than the base material. However, the value of breakdown voltage for both OPEFB and PALF have decreased at the weight percentage of $7.5 \%$ with the DC breakdown voltage values of $54.77 \mathrm{kV}$ for OPEFB while $47.09 \mathrm{kV}$ for PALF. These situations occured because the major problem for cellulose fiber is its own hydrophilic nature and it will influence the mechanical properties of natural fibers [16].

From the electrical properties, the researcher [17] has mentioned that the test had been conducted with 6 times of DC breakdown voltage test by using the samples that contain LLDPE, NR, $\mathrm{SiO} 2$ and TiO2 with the weight percentage of $1 \%, 3 \%, 5 \%$ and $7 \%$. The outcome of the authors said that the higher the weight percentage of the fiber, the higher the DC breakdown voltage will be as it is assumed to have a good resistance to withstand the voltage. So from this test, OPEFB from the species of Elaeis guineensis and PALF from the species of Ananus comosus have shown that the DC breakdown voltage increases when added with several weight percentage of fiber [18]. Furthermore, this test is also conducted by adding $2.5 \%$ of weight percentage to LLDPE and NR where it is compared to the previous research that has been added with $2.0 \%$ of weight percentage to the samples. So the result shows the increment of breakdown voltage compared to the result with $2.0 \%$ of weight percentage for both OPEFB and PALF [19].

The sample material has been designed to be tested with the material size of $9 \mathrm{~cm}$ diameter and $3 \mathrm{~mm}$ thickness [20]. There are many steps that have been carried out before producing the solid material where the material consists of LLDPE, NR, OPEFB and PALF. The total sample of material to be tested is 10 samples.The design of the material are comprised into 100\% of LLDPE, the ratio with $80 \%$ of LLDPE and 20 of rubber, and added with several weight percentage of $2.5 \%, 5.0 \%, 7.5 \%$ and $10.0 \%$ into the compounding of LLDPE+NR [21]. The DC breakdown test that has been done in high voltage (HV) laboratory by following the standard procedure from TERCO [22]. Before conducting the DC breakdown test, risk assessment needed to be filled up as to know the hazard that might occur when carrying out the experiment [23]. From the result it shows that hydrophilic surface can affect the chemical and physical of the material $[24,25]$. By performing detail searching and analysis of this problem, the properties of the material will be able to change from bio-based plastic of non-renewable resources to a renewable resource and it is remarkable to go for the green technologies in the arena of material science over through the biocomposite without harming the environment [26]. 


\section{CONCLUSION}

In this project the development of the sample LLDPE-NR biocomposite material is successful for $\mathrm{HV}$ insulation with the highest breakdown. This DC breakdown test is conducted to distinguish whether the fiber of OPEFB and PALF can replace the coating of the wire cable as an alternative under DC voltages. Two types of fibers that have been used which consists of OPEFB and PALF. The HVDC breakdown test is conducted in order to obtain the value of breakdown voltage and with a constant distance of $3 \mathrm{~mm}$ respectively to thickness of the sample. The results show that the values of breakdown voltage increases when added with the fiber either in OPEFB or PALF. The reference value for pure LLDPE is $54.11 \mathrm{kV}$ while when added with the weight percentage of $2.5 \%$ of fiber, the value of breakdown voltage has increased to $56.40 \mathrm{kV}$ for OPEFB and $58.02 \mathrm{kV}$ for PALF. The analysis that has been constructed through the line graph in Microsoft Excel also showed that the value of DC breakdown voltage has increased until $10 \%$ of weight percentage of fiber. Meanwhile, for the value of weight percentage of $7.5 \%$ DC breakdown voltage has decreased as an effect to the hydrophilic of the nature. Moreover, among both the fiber of OPEFB and PALF, the highest value of breakdown voltage is PALF as the mechanical properties of PALF contains more cellulose when compared to OPEFB as it will become more strengthful and resistive. In conclusion, all the results and analysis are stated at the very beginning are successfully done and completed.

\section{ACKNOWLEDGEMENTS}

The authors gratefully acknowledge Ministry of Higher Education Malaysia for supporting this research under Fundamental Research Grant Scheme for Research Acculturation of Early Career Researchers (FRGS-RACER) Vot No. RACER/1/2019/TK04/UTHM//6, Research Management Centre of Universiti Tun Hussein Onn Malaysia under grant vot K145, TIER 1 vot H090, GPPS vot H025 and Kvolt Focus Group Team, Polymer laboratory in UTHM for the equipment support, Taiko Plantation Sdn Bhd as a supplier Natural Rubber, Lotte Chemical as a supplier LLDPE.

\section{REFERENCES}

[1] E.Kuffel, W.S. Zaengl, J.Kuffel, "High Voltage Engineering Fundamentals, IEEE Power Eng. Rev., vol. 15, no. 5, p. 36, 1995.

[2] T. P. Ying, A. M. Erfeida, C. X. Viet, and D. N. U. Lan, "Effects of filler incorporation routes on mechanical properties of low density polyethylene/natural rubber/silica (LDPE/NR/SI) composites," Appl. Mech. Mater., vol. 679, no. October, pp. 154-157, 2014.

[3] H. X. Wang, Y. L. Wang, and A. Z. Han, "Insulation parameters characteristics of XLPE cable in the course of its aging within CuSO4 electrolyte," 2008 Int. Conf. High Volt. Eng. Appl. ICHVE 2008, pp. 331-334, 2008.

[4] M. H. M. Sharif, N. A. M. Jamail, N. A. Othman, and M. S. Kamarudin, "Analysis of Electric Field and Current Density on XLPE Insulator,” Int. J. Electr. Comput. Eng., vol. 7, no. 6, pp. 3095-3104, 2017.

[5] M. T. S. C. C. WHITE, J. WAGENBLAST, "From Electrical Transmission and Distribution Cable," vol. 40, no. 4, 2000.

[6] J. Barasarathi, P. Agamuthu, C. U. Emenike, and S. H. Fauziah, "Microplastic abundance in selected mangrove forest in Malaysia,” Proceeding ASEAN Conf. Sci. Technol. 2014, June 2015, p. 4, 2011

[7] O. Faruk, A. K. Bledzki, H. P. Fink, and M. Sain, "Biocomposites reinforced with natural fibers: 2000-2010," Prog. Polym. Sci., vol. 37, no. 11, pp. 1552-1596, 2012.

[8] M. H. Ahmad, M. F. Dolmat, N. Bashir, H. Ahmad, and A. A. A. Jamil, "Effects of Oil Palm Empty Fruit Bunch Filler on the Electrical Tree Propagation in Silicone Rubber," APCBEE Procedia, vol. 3, no. May, pp. 147-153, 2012.

[9] Farrah Diyana Zailan, Ruey Shan Chen, Shahrin Ahmad Shahdan, Adilah Mat Ali, Mohd Farid Hakim Mohd Ruf, "Blends of Linear Low-Density Polyethylene, Natural Rubber and polyaniline: Tensile properties and thermal stability", Vol 22, No 6, pp.1,28 April 2018.

[10] N. A. M. Jamail, N. A. A. N. Zarujhan, and N. A. Muhamad, "Breakdown characteristic of LLDPE-NR nanocomposite using high voltage direct, current (HVDC) test," Int. J. Simul. Syst. Sci. Technol., vol. 17, no. 41, pp. 38.1-38.5, 2016.

[11] M. H. Ahmad et al., "Oil Palm Empty Fruit Bunch as a New Organic Filler for Electrical Tree Inhibition," Oil Palm Empty Fruit Bunch as a New Org. Fill. Electr. Tree Inhib., vol. 6, no. 2, pp. 197-202, 2012.

[12] Rahul Kher, Dr Nikhil Gondaliya, Mukesh Bhesanya, Latif Ladid, Mohammed Atiquazzaman, "Proceedings of the International Conference on Intelligent Systems and Signal Processing”, vol 671, pp 246, 2017.

[13] A. Andersen and J. Dennison, "Highly Accelerated Test Method for Characterizing Likelihood of Breakdown in HVDC Dielectric Materials", IEEE Transactions on Electrical Insulation and Dielectric Phenomena". March, 2017.

[14] S. Agarwal, C. K. Panigrahi, A. Sahoo, and S. Mishra, "A novel study on bipolar high voltage direct current transmission lines protection schemes," Int. J. Electr. Comput. Eng., vol. 8, no. 4, pp. 1977-1984, 2018.

[15] S. Karuppannan Gopalraj and T. Kärki, "A review on the recycling of waste carbon fibre/glass fibre-reinforced composites: fibre recovery, properties and life-cycle analysis," SN Appl. Sci., vol. 2, no. 3, pp. 1-21, 2020. 
[16] L. Mohammed, M. N. M. Ansari, G. Pua, M. Jawaid, and M. S. Islam, "A Review on Natural Fiber Reinforced Polymer Composite and Its Applications," Int. J. Polym. Sci., vol. 2015.

[17] A. Paramane, X. Chen, C. Dai, H. Guan, L. Yu, and Y. Tanaka, "Electrical insulation performance of cross-linked polyethylene $/ \mathrm{MgO}$ nanocomposite material for $\pm 320 \mathrm{kV}$ high-voltage direct-current cables," Polym. Compos., vol. 41, no. 5, pp. 1936-1949, 2020.

[18] M. Asim et al., "A review on pineapple leaves fibre and its composites," Int. J. Polym. Sci., vol. 2015, no. April, 2015.

[19] M. J. John and S. Thomas, "Biofibres and biocomposites," Carbohydr. Polym., vol. 71, no. 3, pp. 343-364, 2008.

[20] M. I. H. M. Razali, N. A. M. Jamail, M. A. A. Azmi, N. H. Zulkifli, and N. A. A. N. Zarujhan, "Insulation characteristic of LLDPE-NR compound with MMT/clay nanofiller for HV insulation +++++++++purposes," ARPN J. Eng. Appl. Sci., vol. 11, no. 8, pp. 5007-5011, 2016.

[21] M. Zul and H. Makmud, "Natural Rubber as Electrical Insulator: A Review Akademia Baru Natural Rubber as Electrical Insulator : A Review," vol. 6, no. February 2015, pp. 28-42, 2016.

[22] R. G. Olsen, M. W. Tuominen, and J. T. Leman, "On Corona Testing of High-Voltage Hardware Using Laboratory Testing and/or Simulation," IEEE Trans. Power Deliv., vol. 33, no. 4, pp. 1707-1715, 2018.

[23] T. Aven, "Risk assessment and risk management: Review of recent advances on their foundation," Eur. J. Oper. Res., vol. 253, no. 1, pp. 1-13, 2016.

[24] J. Drelich, E. Chibowski, D. D. Meng, and K. Terpilowski, "Hydrophilic and superhydrophilic surfaces and materials," Soft Matter, vol. 7, no. 21, pp. 9804-9828, 2011.

[25] N. A. M. Jamail, M. A. M. Piah, N. A. Muhammad, and Q. E. Kamarudin, "PDC analysis of LLDPE-NR nanocomposite for effect of moisture absorption," Int. J. Electr. Comput. Eng., vol. 7, no. 6, pp. 3133-3139, 2017.

[26] M. Y. Mat Zain, M. T. Ali, and A. N. H. Hussin, "High Voltage Durability of Bambusa Vulgaris as a Bio-composite Material," Int. J. Electr. Comput. Eng., vol. 8, no. 5, p. 2643, 2018. 